\title{
CERN'S 400 GeV Super Proton Synchrotron
}

\author{
JOHN B. ADAMS, FRS, B. SOUTHWORTH, R. BILLINGE, \\ R. LEVY-MANDEL, J. GERVAISE, O. BAYARD, E. HUGI AND \\ M. C. CROWLEY-MILLING \\ CERN, Geneva, Switzerland
}

\begin{abstract}
Macroengineering projects are not normally constructed with accuracies measured in fractions of millimetre nor do they take the curvature of the Earth into consideration. CERN's Super Froton Synchrotron near Genera, Switzerland, required both and yet it was built within the time and cost estimated. When commissioned it worked first time and has since then exceeded expectations. Here the details of its interdisciplinary design and construction are recorded by the Project Team who were responsible for this success story. The articles deal with the magnets, the vacuum system, the radiofrequency acceleration system, the civil engineering aspects of the $6.9 \mathrm{~km}$ tunnel, its survey and alignment, the voltage stabilization of the power supply, the cooling water system, and last but by no means least the novel computer control philosophy and techniques which may well find application in other complex projects nceding monitoring and control.
\end{abstract}

A very large particle accelerator like the $400 \mathrm{GeV}$ Super Proton Synchrotron, SPS, at CERN, which is described in the following articles, involves many technologies and many disciplines. If, as was the case, it is built on an iniernational basis, it also involves a decision making procedure in which many countries take part. CERN is a European Organization with twelve Member States and a proposal to construct this very high energy proton accelerator was first out to the delegates of the twelve Member States at a CERN Council meeting in 1963. A detailed project report was submitted the year afterwards. However, it was not until the beginning of 1971 that the CERN Council finally gave its approval to the project, and by that time the design of the accelerator had changed considerably.

The reasons for the long delay in reaching a decision to construct the SPS were the very high cost of the original project, the difficulty in agreeing on a site for the new machine, and the uncertain future of the existing CERN Laboratory near Geneva once the new machine became operational. The changes proposed in the project which was finally accepted by the CERN Council were aimed at avoiding these problems. By building the new machine next to the existing CERN Laboratory considerable reductions could be made in the project costs since many of the existing installations and all of the services of the existing laboratory could be used for the new

CCC-0308-0188/78/0003-03:2\$10.10/! machine. The existing laboratory therefore became part of the new project and its future was no longein doubt. Furthermore, the cost reductions could only be realized on the site proposed, and hence there was no problem in choosing a site.

However, it took several years to reach this conciusion and to gain the agreement of the Member States of CERN; longer than it took to construct the SPS and to reach full beam energy.

The technologies involved in the SPS project cover a very wide field indeed. Because of the site contours and the stability requirements of the machine, the SPS is installed in turnels deep underground which were bored in the undorlying rock. The precision boring of the main ring tunnel, about $7 \mathrm{~km}$ in circumference, was carried out with a fullfaced boring machine, and the guidance system for this boring machine, using the Farth's rotational axis as the fundamental reference, required a number of new developments described below. Similarly, the survey system set up in this tunnel to align the many thousands of components of the machine is novel. Components suci as the magnet sistem. the higi frequency accelerating system, the vacuum system. and the proton injection, extraction and transport systems all requited major extensions to existing technologies. The control system, which involves 24 control computers connected through a high speed message switching system, is one of the most advanced in the world. 